\title{
Incidence of atrial fibrillation in whites and African-Americans: the Atherosclerosis Risk in Communities (ARIC) Study
}

\author{
Alvaro Alonso, MD, $\mathrm{PhD}^{1}$, Sunil K. Agarwal, MD, $\mathrm{MPH}^{2}$, Elsayed Z. Soliman, MD, MSc, $\mathrm{MS}^{3}$, \\ Marietta Ambrose, MD ${ }^{4}$, Alanna M. Chamberlain, MPH ${ }^{1}$, Ronald J. Prineas, MD, PhD $^{3}$, and \\ Aaron R. Folsom, MD, MPH ${ }^{1}$ \\ ${ }^{1}$ Division of Epidemiology and Community Health, School of Public Health, University of Minnesota, \\ Minneapolis, MN \\ ${ }^{2}$ Department of Epidemiology, Gillings School of Global Public Health, University of North Carolina, \\ Chapel Hill, NC \\ ${ }^{3}$ Department of Epidemiology, Division of Public Health Sciences, Wake Forest University School \\ of Medicine, Winston-Salem, NC \\ ${ }^{4}$ Johns Hopkins Bloomberg School of Public Health, Baltimore, MD
}

\begin{abstract}
Objectives-To define the incidence and cumulative risk of atrial fibrillation (AF) in a populationbased cohort of whites and African-Americans.

Background-African-Americans reportedly have a lower risk of AF than whites despite their higher exposure to AF risk factors. However, precise estimates of AF incidence in African-Americans have not been previously published.

Methods-We studied the incidence of AF in the Atherosclerosis Risk in Communities Study, which has followed up 15,792 men and women aged 45-65 at baseline from four communities in the United States since 1987. AF cases were identified from ECGs conducted at baseline and three follow-up visits, and from hospitalizations and death certificates through the end of 2004. During follow-up, 1,085 new cases of AF were identified (196 in African-Americans, 889 in whites).
\end{abstract}

\begin{abstract}
Results-Crude incidence rates of AF were 6.7, 4.0, 3.9 and 3.0 per 1,000 persons per year in white men, white women, African-American men and African-American women, respectively. Increasing age was exponentially associated with an elevated risk of AF. Compared to whites, African-

Americans had a 41\% (95\% confidence interval: $8 \%-62 \%$ ) lower age- and sex-adjusted risk of being diagnosed with $\mathrm{AF}$. The cumulative risk of AF at age 80 was $21 \%$ in white men, $17 \%$ in white women, and $11 \%$ in African-American men and women.
\end{abstract}

Conclusion-In this population-based cohort, African-Americans presented a lower risk of AF than whites. Still, the burden of AF among the former is substantial, with 1 in 9 receiving a diagnosis of AF before the age of 80 .

\footnotetext{
Address for correspondence: Dr. Alvaro Alonso, MD, PhD. Division of Epidemiology and Community Health. School of Public Health. University of Minnesota. 1300 S $2^{\text {nd }}$ St, Suite 300. Minneapolis, MN 55454. Phone: +16166268597 . Fax: +16126240315 . Email: Email: aalogut@alumni.unav.es.

Publisher's Disclaimer: This is a PDF file of an unedited manuscript that has been accepted for publication. As a service to our customers we are providing this early version of the manuscript. The manuscript will undergo copyediting, typesetting, and review of the resulting proof before it is published in its final citable form. Please note that during the production process errors may be discovered which could affect the content, and all legal disclaimers that apply to the journal pertain.
} 


\section{Keywords}

atrial fibrillation; epidemiology; incidence; African-Americans; lifetime risk

\section{Introduction}

Atrial fibrillation (AF) is the most frequent sustained cardiac arrhythmia seen in clinical practice. It also increases the risk of cardiovascular disease, particularly stroke, and overall mortality $(1,2)$. Prevalence estimates suggest that, in the United States (US) alone, more than 2 million individuals have AF. This figure is projected to double by 2050 (3). The magnitude of the problem could be even larger as suggested by recent trends of increasing AF incidence $(4,5)$.

Still, questions remain on the epidemiology of AF, particularly among non-whites. Existing data on the incidence and lifetime risk of AF in the general US population is limited mostly to whites $(4,6-8)$. Different reports suggest that the burden of AF is lower among AfricanAmericans $(3,9,10)$, despite their higher prevalence of potential risk factors for AF, such as hypertension or obesity $(11,12)$. Regrettably, precise figures for incidence of AF in this racial group are not available.

In order to define more precisely the occurrence of AF in the general white and AfricanAmerican population in the US, including assessment of temporal trends, we estimated the incidence of AF in the Atherosclerosis Risk in Communities (ARIC) study, a biracial, population-based, prospective study with more than 15,000 participants.

\section{Methods}

\section{Study population}

The ARIC study is a population-based prospective study of cardiovascular disease in a cohort of 15,792 participants, aged 45 to 64 at enrollment (55\% women, 27\% African American). Participants were sampled from 4 US communities (mostly whites from suburbs of Minneapolis, Minnesota and Washington County, Maryland; African-Americans from Jackson, Mississippi; and whites and African-Americans from Forsyth County, North Carolina) during the period 1987-89 (13). After an initial assessment, study participants were examined 3 additional times at intervals of roughly 3 years. In addition, participants are contacted yearly by phone to obtain information about hospital admissions and ascertain vital status. Response rates for exams 2, 3, and 4 were respectively $93 \%, 86 \%$, and $80 \%$. Average response rate to the annual follow-up interviews after exam 4 is higher than $90 \%$ among survivors. For this analysis, we excluded individuals whose race was neither African American nor white $(\mathrm{n}=48)$, a few African-Americans from the Minneapolis and Washington County sites $(\mathrm{n}=55)$, and those with electrocardiogram (ECG)-diagnosed $\mathrm{AF}$ at the initial examination $(n=37)$ or without an ECG examination $(n=245)$. The study was approved by institutional review boards at each participating center. Written informed consent was obtained from all participants.

\section{AF ascertainment}

AF diagnoses were obtained from three sources: ECGs at four study exams, hospital discharge records, and death certificates. Study participants underwent ECG recordings at baseline and at each follow-up exam. All ECG recordings were done with MAC PC Personal Cardiographs (Marquette Electronics, Inc., Milwaukee, WI). A standard supine 12-lead resting ECG was recorded after a 12-hour fast followed by a light snack and at least one hour after smoking 
tobacco or ingestion of caffeine. ECGs were transmitted by telephone to the ARIC Central ECG Reading Center for coding, interpretation and storage. All ECG recordings automatically coded as AF were visually re-checked by a trained cardiologist to confirm the diagnosis (14).

As part of standard follow-up procedures in ARIC, a trained abstractor obtained and recorded all ICD-9 hospital discharge diagnoses from each participant's hospitalizations reported in the annual follow-up interview. AF was defined as the presence of ICD-9 code 427.31 in the discharge codes. Patients with a diagnosis of atrial flutter (ICD-9 code 427.32) not developing $\mathrm{AF}$ in subsequent follow-up were not considered cases ( $\mathrm{n}=53$ cases). Transient AF can occur during cardiac operative procedures. Therefore, we excluded AF hospitalization diagnoses occurring simultaneously with heart revascularization surgery (ICD-9 code 36.X) or other cardiac surgery involving heart valves or septa (ICD-9 code 35.X), without evidence of AF in subsequent hospitalizations or study exams ( $\mathrm{n}=86$ cases). ARIC participants were also labeled as AF cases if the underlying cause of death was AF (ICD-10 code I48 or ICD-9 code 427.3).

Two analyses were done to determine the validity of the diagnosis of incident AF based on hospital discharges. First, a sample of 125 hospital discharge summaries in the Minnesota, Forsyth County and Washington County field centers with a first ICD-9 code for AF together with ECGs performed during that hospitalization was reviewed by a study physician. The hospital discharge record and the ECGs confirmed the diagnosis of AF in 111 cases (89\%). Seventy-eight (70\%) were referred to as AF of new onset. Second, we used information collected in the usual procedures for stroke ascertainment in ARIC. In each suspected case of stroke, a trained abstractor filled a form with data from the complete medical record. This form includes information on the presence of AF during or 4 weeks before the hospitalization. Of 161 individuals with AF recorded in the stroke abstraction form, 135 had an ICD code for AF (sensitivity=84\%). Similarly, of 1,385 without AF in the abstraction form, $34(2 \%)$ had the ICD code for $\mathrm{AF}$ ( (specificity $=98 \%$ ). In African-Americans, sensitivity was $80 \%$ and specificity 99\%; in whites, the corresponding figures were $85 \%$ and $97 \%$.

The incidence date of AF was defined as the date for the first ECG showing AF, the first hospital discharge with an $\mathrm{AF}$ or atrial flutter diagnosis (the latter only if $\mathrm{AF}$ was identified later in the same patient), or death by AF, whichever occurred earlier.

\section{Assessment of other variables}

At baseline, cigarette smoking, blood pressure, antihypertensive medication use, diabetes, weight, and height were measured using standardized methods (13). Hypertension was defined as a blood pressure of $140 / 90 \mathrm{mmHg}$ or higher or current use of antihypertensive medication. ECG-diagnosed left ventricular hypertrophy was considered present if the Cornell voltage was $>28 \mathrm{~mm}$ in men or $>22 \mathrm{~mm}$ in women (15). History of myocardial infarction at baseline was defined as a self-reported history of a physician-diagnosed myocardial infarction, or evidence of previous myocardial infarction in the baseline ECG.

\section{Statistical analysis}

We computed person-years of follow-up from the date of the first examination to a first diagnosis of AF, death, lost to follow-up, or December 31, 2004, whichever came earlier. Person-years of follow-up were allocated to race- (whites, African-Americans), age- (in 5-year periods) and sex-specific groups. Specific incidence rates of AF were estimated dividing the number of new cases of AF in each group by the corresponding person-years.

We estimated incidence rate ratios (RR) of AF and their $95 \%$ confidence intervals (CI) by age, sex, race, and study period (in years) fitting Poisson regression models, with age (in 5-year groups), sex, race, field center, and period (study year) as independent variables, and AF 
incidence as the outcome. Additionally, we plotted age-specific incidence rates of AF by 4year periods to assess visually the existence of temporal trends. Because the last study ECG was done in 1998, these period analyses only included cases identified through hospital discharge codes to avoid an artificial higher incidence of AF in the first decade of follow-up due to AF cases diagnosed by ECGs performed at study exams.

To summarize stratum-specific incidence rates, we estimated the cumulative risk of AF up to age 80, applying the same methodology previously used in the Framingham Heart Study to compute lifetime risk of AF adjusting for the competing risk of death $(8,16)$. Because few individuals were followed up after age 80 , we estimated risk of AF through that age, starting from ages 50,60 and 70. Calculations were conducted separately for African-American and whites, and for men and women.

All statistical analyses were performed with SAS v 9.1 (SAS Inc, Cary, NC).

\section{Results}

Of 15,792 ARIC participants, 15,444 met eligibility criteria. At the baseline examination, 37 $(0.2 \%)$ of them had AF in their ECG. Therefore, these individuals were excluded from the incidence calculations. Selected baseline characteristics of the study sample are shown in table 1. Prevalence of cardiovascular risk factors, such as hypertension, diabetes, left ventricular hypertrophy, body mass index and smoking, was higher in African-Americans than whites. From 1987 to 2004, during 228,976 person-years of follow-up, 1,085 new cases of AF were identified in the ARIC study. Table 2 shows the distribution of AF incident cases according to the different sources of endpoint ascertainment. Most AF cases (88\%) were identified through hospital discharge codes only.

Incidence of AF increased exponentially with age, and was higher in men compared to women and whites compared to African-Americans (table 3). Site-specific incidence rates, standardized by age and sex, were 5.5 per 1,000 person-years for whites in Washington County, 4.5 for whites in Minneapolis, 5.2 for whites in Forsyth County, 2.9 for African-Americans in Forsyth County, and 3.8 for African-Americans in Jackson. Incidence estimates in ARIC were similar to those obtained from other population-based cohorts in the US (figure 1) $(4,6,7)$.

The RR (95\% CI) of AF in men versus women was $1.54(1.37,1.74)$. Risk of AF in AfricanAmericans was $41 \%$ lower than in whites ( $R R=0.59,95 \%$ CI $0.38,0.92)$. The gender difference was slightly larger in whites than African-Americans: the RR of AF in men compared to women was $1.61(95 \%$ CI $1.40,1.83)$ in whites, while it was $1.29(0.97,1.72)$ in African-Americans ( $\mathrm{p}$ for interaction=0.15). In an analysis including only AF cases identified in ECGs performed at study visits, African-Americans still had a lower incidence of $\mathrm{AF}(\mathrm{RR}=0.35,95 \%$ CI 0.19 , $0.64)$. Finally, age-specific AF incidence did not appreciably change over the study period ( $\mathrm{p}$ for trend $=0.40$ ) (table 4 and figure 2 ).

The cumulative risk of developing $\mathrm{AF}$ at age 80 if an individual was free of $\mathrm{AF}$ at age 50 was $21 \%$ in white men, $17 \%$ in white women, and $11 \%$ in both African-American men and women (figure 3). AF cumulative risk did not change appreciably across index ages because most of the increase in rates occurs late in life. For example, risk of AF at age 80 if free of AF at age 70 was $16 \%$ in white men, $13 \%$ in white women, $9 \%$ in African-American men, and $10 \%$ in African-American women.

\section{Discussion}

In this analysis of the ARIC cohort, we show that incidence of AF is higher in whites than in African-Americans, despite risk factors for AF being more prevalent in the latter group. 
Incidence rates of $\mathrm{AF}$ among whites in the ARIC study were comparable to those obtained in other population-based studies conducted in the US $(4,6,7)$. Consistent with previous publications, AF rates increased exponentially with age and were higher in men than women. Finally, we estimated the cumulative risk of AF at age 80 to be twice as high in white men as in African-Americans, with white women having an intermediate risk. No temporal trends were evident in the incidence of AF.

Previous reports consistently suggest that African-Americans have lower prevalence and incidence of AF compared to whites. In the population aged 50 or older enrolled in Kaiser Permanente of Northern California, AF prevalence in African-Americans was 32\% lower than in whites (3). Similarly, elderly African-Americans in the Cardiovascular Health Study had a $53 \%$ lower risk of incident AF compared to whites (7). Other data sources provide parallel results. In the US National Hospital Ambulatory Medical Care Survey, rates of visits to an emergency department with AF as the primary diagnosis were higher in whites than in AfricanAmericans (9 vs. 5 per 10,000 person-year) (9). The National Hospital Discharge Survey, which compiles data on discharges from nonfederal hospitals in the US, also shows a higher incidence of AF hospitalizations in whites than in African-Americans (17). This racial difference in the incidence of AF has been also evidenced in heart failure patients enrolled in the Epidemiology, Practice, Outcomes, and Costs of Heart Failure (EPOCH) study, where African-Americans had a 50\% lower prevalence of AF than whites even after adjustment for known risk factors for $\mathrm{AF}$ (18). Our findings are consistent with previous evidence, providing for the first time age-specific incidence rates of $\mathrm{AF}$ in a population-based study of white and African-American middle age adults.

We can only guess at the mechanisms underlying the reported lower burden of AF in AfricanAmericans, particularly considering that prevalence of some risk factors for AF, such as hypertension, is higher among this racial group. Underascertainment of AF in AfricanAmericans because of poorer access to medical care could explain the divergence (19). However, this would not be operable in the finding of racial differences in the Kaiser Permanente study, where all participants presumably had similar access to healthcare (3), and could not explain the lower risk of AF in the ARIC African-American sample when including only cases identified through ECGs done at study visits. Differential mortality, also, might account for part of the discrepancy. Total and cardiovascular disease mortality is higher among African-Americans than whites (20), which in turn could lead to lower AF incidence in the former group if the increased mortality affected disproportionably individuals susceptible to develop AF. In this regard, it has been shown that post-myocardial infarction mortality is higher among African-Americans than whites (35\% v. 30\% among patients admitted to hospitals with revascularization service) (21), increasing the proportion of myocardial infarction survivors, and hence patients at higher risk of AF, among whites. Nonetheless, the magnitude of this difference is not enough to explain a 50\% lower cumulative risk of AF among AfricanAmericans. Another explanation for the racial differences could be a relative higher incidence of paroxysmal (vs. permanent) AF among African-Americans compared to whites (22). In the Group Health Cooperative study, a population-based study of newly detected AF in a large health plan, the proportion of whites among sustained AF cases was higher than among transitory/intermittent AF cases, though these differences were small and not significant (23). Geographic disparities in medical practice across the different ARIC sites could explain differences between races, though the only study site including both racial groups, Forsyth County, had a 78\% higher rate of AF in whites than African-Americans, not supporting this hypothesis. Finally, pathophysiological mechanisms could account for the differences. For example, in the Cardiovascular Health Study, white men had on average a larger left atrium than their African-American counterparts (24), and a larger left atrium was associated with an increased risk of $\mathrm{AF}$ in this same population (7). Also, genetic traits associated with increased 
risk of AF could be disproportionally prevalent in whites. No published studies, however, have compared genetic risk factors in whites and African-Americans.

Previous reports suggest that the burden of AF in the population might be increasing. In the Framingham Heart Study, age-adjusted prevalence of AF in men aged 65-84 increased from $3.2 \%$ in $1968-1970$ to $9.1 \%$ in $1987-1989$, and from $2.8 \%$ to $4.7 \%$ in women during the same period (25). Similar results were observed in Olmsted County, Minnesota, where age-adjusted prevalence of AF in men and women rose from 5\% and 4\%, respectively, in the decade 1960-69 to $12 \%$ and $8 \%$ in the decade $1980-89$ (26). These observations could result from an increase in AF incidence, from longer survival of patients with AF, or from both. An analysis of the National Discharge Survey, in the United States, found a 2- to 3-fold increase in hospitalization rates for AF from 1985 to 1999 (5), but this survey did not differentiate between incident and prevalent cases. More interestingly, recent findings from Olmsted County, Minnesota, implied that incidence of AF could be on the rise: In an analysis including 4,618 cases, AF incidence increased $12 \%$ between 1980 and 2000 (4). In the ARIC cohort, we did not find a significant increase in AF incidence. This could be due to the limited number of cases, to differences between the studied populations, such as age and race distribution or prevalence and treatment of AF risk factors, or to the shorter period of time included in the ARIC follow-up.

A major limitation of the present analysis is the method of AF ascertainment, mostly based on hospital discharge codes. This could lead, on one hand, to underascertainment of AF cases not requiring hospitalization. Unfortunately, no published evidence provides information to estimate the proportion of AF cases missed because of lack of outpatient diagnoses. On the other hand, our hospital-based AF ascertainment could lead to false positives. In the Cardiovascular Health Study, 98\% of the AF cases identified through hospital discharge codes were confirmed through review of discharge summaries (7). In the ARIC cohort, however, we were able to confirm only $89 \%$ of a sample of 125 discharge summaries. Additionally, we estimated that the sensitivity of the ICD code of AF in the hospital discharge summary of participants with suspected stroke was $84 \%$, slightly higher for whites but not enough to explain the important difference in incidence rates. Still, AF incidence and lifetime risk in the white ARIC participants were extremely similar to those from other populations, such as the Mayo Clinic study in Olmsted County, Minnesota, or the Framingham Heart Study $(4,8)$.

The present analysis has several important strengths. First, its large sample size and extended follow-up allowed the estimation of precise incidence rates, specifically in the AfricanAmerican population. Second, the ARIC cohort is approximately representative of the underlying populations, providing excellent generalizability of the results. The race-specific incident rates of $\mathrm{AF}$ presented here could be used to update projections of AF prevalence in the United States, taking into account the lower burden of AF in African-Americans.

In conclusion, we report incidence rates of $\mathrm{AF}$ in a population-based sample of four different US communities including a sizeable number of African-Americans. These results highlight the high impact of AF in the general population, particularly among older individuals, and serve as a call to action for the development of effective preventive strategies. Future studies comparing risk factors for AF in whites and African-Americans are needed to provide insights into the mechanisms explaining the racial discrepancy.

\section{Acknowledgments}

The authors thank the ARIC participants, staff, and investigators for their long-term contributions to ARIC.

Sources of funding: This research was sponsored by National Heart, Lung, and Blood Institute (NHLBI) contracts N01-HC-55015, 55016, 55018, 55019, 55020, 55021, and 55022. Alanna M. Chamberlain was supported by NHLBI 
grant T32-HL-007779. The authors are solely responsible for the design and conduct of this study, all study analyses, the drafting and editing of the paper and its final contents.

\section{References}

1. Rosamond W, Flegal K, Furie K, et al. Heart disease and stroke statistics--2008 update: a report from the American Heart Association Statistics Committee and Stroke Statistics Subcommittee. Circulation 2008;117:e25-146. [PubMed: 18086926]

2. Benjamin EJ, Wolf PA, D'Agostino RB, Silbershatz H, Kannel WB, Levy D. Impact of atrial fibrillation on the risk of death: the Framingham Heart Study. Circulation 1998;98:946-952. [PubMed: 9737513]

3. Go AS, Hylek EM, Phillips KA, et al. Prevalence of diagnosed atrial fibrillation in adults. National implications for rhythm management and stroke prevention: the Anticoagulation and Risk Factors in Atrial Fibrillation (ATRIA) study. Journal of the American Medical Association 2001;285:2370-2375. [PubMed: 11343485]

4. Miyasaka Y, Barnes ME, Gersh BJ, et al. Secular trends in incidence of atrial fibrillation in Olmsted County, Minnesota, 1980 to 2000, and implications on the projections for future prevalence. Circulation 2006;114:119-125. [PubMed: 16818816]

5. Wattigney WA, Mensah GA, Croft JB. Increasing trends in hospitalization for atrial fibrillation in the United States, 1985 through 1999. Implications for primary prevention. Circulation 2003;108:711716. [PubMed: 12885749]

6. Benjamin EJ, Levy D, Vaziri SM, D'Agostino RB, Belanger AJ, Wolf PA. Independent risk factors for atrial fibrillation in a population-based cohort. The Framingham Heart Study. Journal of the American Medical Association 1994;271:840-844. [PubMed: 8114238]

7. Psaty BM, Manolio TA, Kuller LH, et al. Incidence of and risk factors for atrial fibrillation in older adults. Circulation 1997;96:2455-2461. [PubMed: 9337224]

8. Lloyd-Jones DM, Wang TJ, Leip EP, et al. Lifetime risk for development of atrial fibrillation. The Framingham Heart Study. Circulation 2004;110:1042-1046. [PubMed: 15313941]

9. McDonald AJ, Pelletier AJ, Ellinor PT, Camargo CA Jr. Increasing US emergency department visit rates and subsequent hospital admissions for atrial fibrillation from 1993 to 2004. Annals of Emergency Medicine 2008;51:58-65. [PubMed: 17466409]

10. Wattigney WA, Mensah GA, Croft JB. Increased atrial fibrillation mortality: United States, 1980-1998. American Journal of Epidemiology 2002;155:819-826. [PubMed: 11978585]

11. Hertz RP, Unger AN, Cornell JA, Saunders E. Racial disparities in hypertension prevalence, awareness, and management. Archives of Internal Medicine 2005;165:2098-2104. [PubMed: 16216999]

12. Ogden CL, Carroll MD, Curtin LR, McDowell MA, Tabak CJ, Flegal KM. Prevalence of overweight and obesity in the United States, 1999-2004. Journal of the American Medical Association 2006;295:1549-1555. [PubMed: 16595758]

13. The ARIC Investigators. The Atherosclerosis Risk in Communities (ARIC) study: design and objectives. American Journal of Epidemiology 1989;129:687-702. [PubMed: 2646917]

14. Soliman EZ, Prineas RJ, Case D, Zhang ZM, Goff DC Jr. Ethnic distribution of electrocardiographic predictors of atrial fibrillation and its impact on understanding the ethnic distribution of ischemic stroke in the Atherosclerosis Risk in Communities Study (ARIC). Stroke. 2008in press

15. Casale PN, Devereux RB, Alonso DR, Campo E, Kligfield P. Improved sex-specific criteria of left ventricular hypertrophy for clinical and computer interpretation of electrocardiograms: validation with autopsy findings. Circulation 1987;75:565-572. [PubMed: 2949887]

16. Beiser A, D'Agostino RB Sr, Seshadri S, Sullivan LM, Wolf PA. Computing estimates of incidence, including lifetime risk: Alzheimer's disease in the Framingham Study. The Practical Incidence Estimators (PIE) macro. Statistics in Medicine 2000;19:1495-1522. [PubMed: 10844714]

17. Khairallah F, Ezzedine R, Ganz LI, London B, Saba S. Epidemiology and determinants of outcome of admissions for atrial fibrillation in the United States from 1996 to 2001. American Journal of Cardiology 2004;94:500-504. [PubMed: 15325940] 
18. Ruo B, Capra AM, Jensvold NG, Go AS. Racial variation in the prevalence of atrial fibrillation among patients with heart failure. Journal of the American College of Cardiology 2004;43:429-435. [PubMed: 15013126]

19. Rehman SU, Hutchison FN, Hendrix K, Okonofua EC, Egan BM. Ethnic differences in blood pressure control among men at Veterans Affairs clinics and other health care sites. Archives of Internal Medicine 2005;165:1041-1047. [PubMed: 15883244]

20. Williams JE, Massing M, Rosamond WD, Sorlie PD, Tyroler HA. Racial disparities in CHD mortality from 1968-1992 in the state economic areas surrounding the ARIC Study communities. Annals of Epidemiology 1999;9:472-480. [PubMed: 10549880]

21. Popescu I, Vaughan-Sarrazin MS, Rosenthal GE. Differences in mortality and use of revascularization in black and white patients with acute MI admitted to hospitals with and without revascularization services. Journal of the American Medical Association 2007;297:2489-2495. [PubMed: 17565083]

22. Soliman EZ, Goff DC Jr. Paradox of racial distribution of atrial fibrillation. Journal of the National Medical Association 2008;100:447-448. [PubMed: 18484116]

23. Glazer NL, Dublin S, Smith NL, et al. Newly detected atrial fibrillation and compliance with antithrombotic guidelines. Archives of Internal Medicine 2007;167:246-252. [PubMed: 17296879]

24. Manolio TA, Gottdiener JS, Tsang TSM, Gardin JM, Cardiovascular Health Study Collaborative Research Group. Left atrial dimensions determined by M-mode echocardiography in black and white older ( $>=65$ years) adults (the Cardiovascular Health Study). American Journal of Cardiology 2002;90:983-987. [PubMed: 12398966]

25. Wolf PA, Benjamin EJ, Belanger AJ, Kannel WB, Levy D, D'Agostino RB. Secular trends in the prevalence of atrial fibrillation: the Framingham Study. American Heart Journal 1996;131:790-795. [PubMed: 8721656]

26. Tsang TSM, Petty GW, Barnes ME, et al. The prevalence of atrial fibrillation in incident stroke cases and matched population controls in Rochester, Minnesota: Changes over three decades. Journal of the American College of Cardiology 2003;42:93-100. [PubMed: 12849666] 
A.

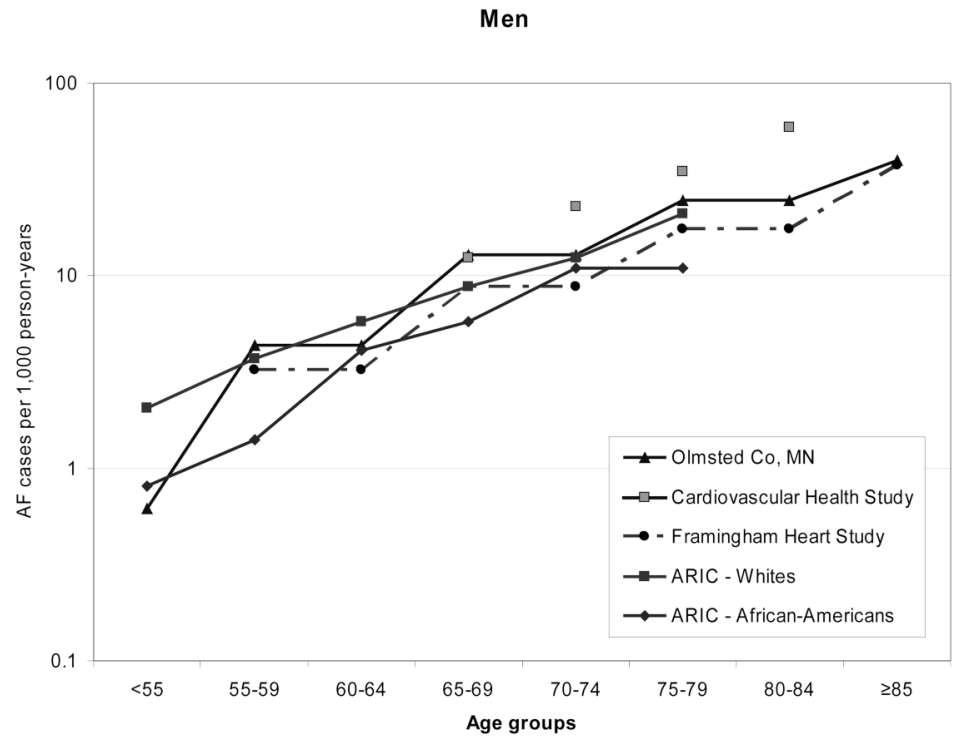

B.

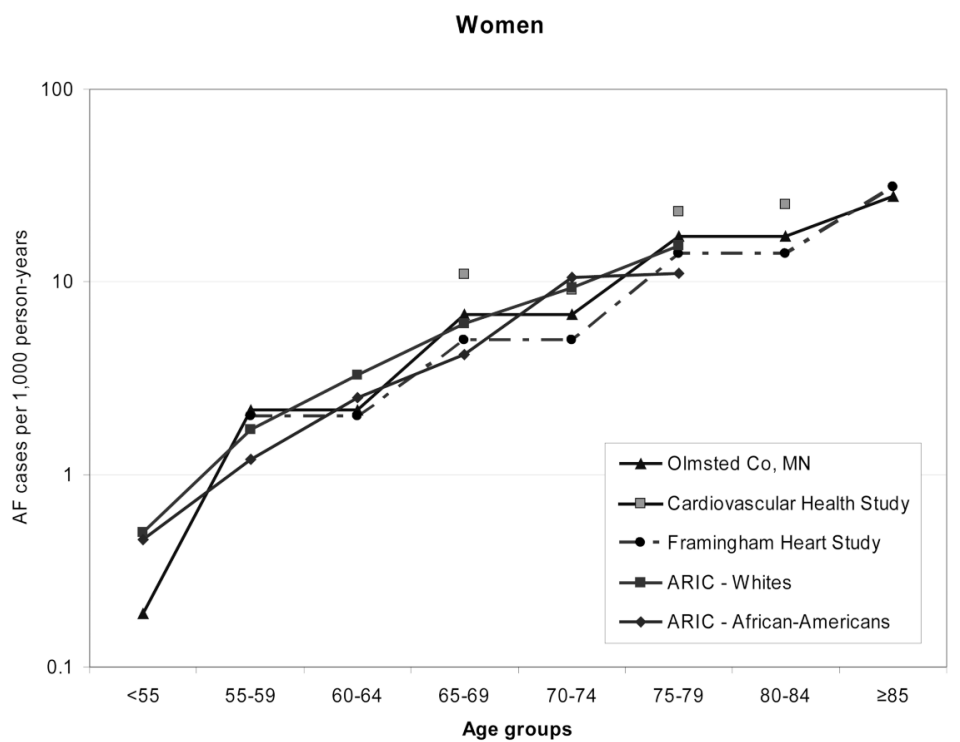

Figure 1.

Age- and sex-specific incidence rates of atrial fibrillation (AF) in population-based studies in the United States. Rates for the Cardiovascular Health Study include both whites and AfricanAmericans; their race-specific rates have not been published. 


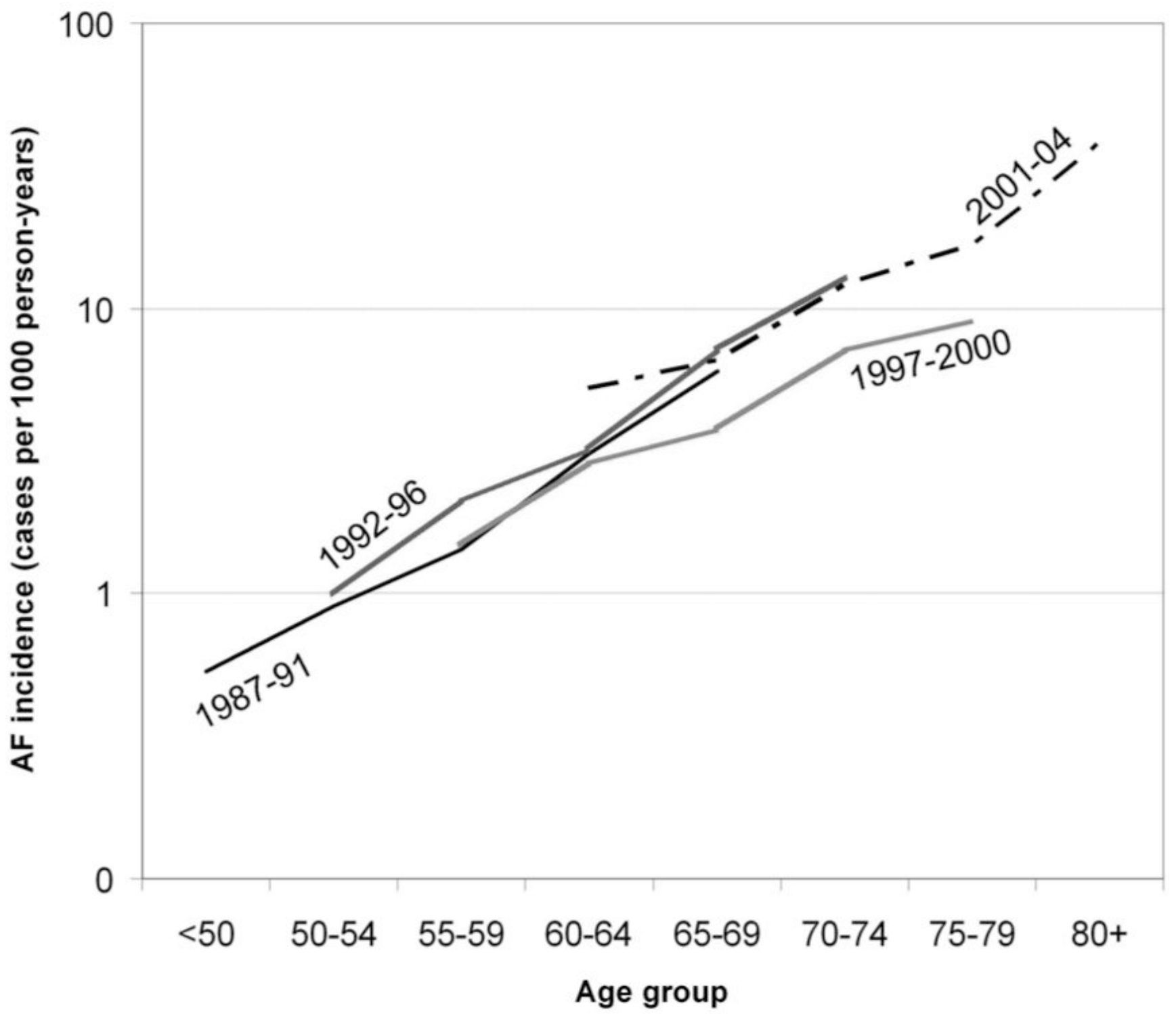

Figure 2.

Age-specific incidence rates of atrial fibrillation (AF) by study period, Atherosclerosis Risk in Communities Study, 1987-2004. Rates are standardized to the overall gender and race distribution in the study sample. 
White men

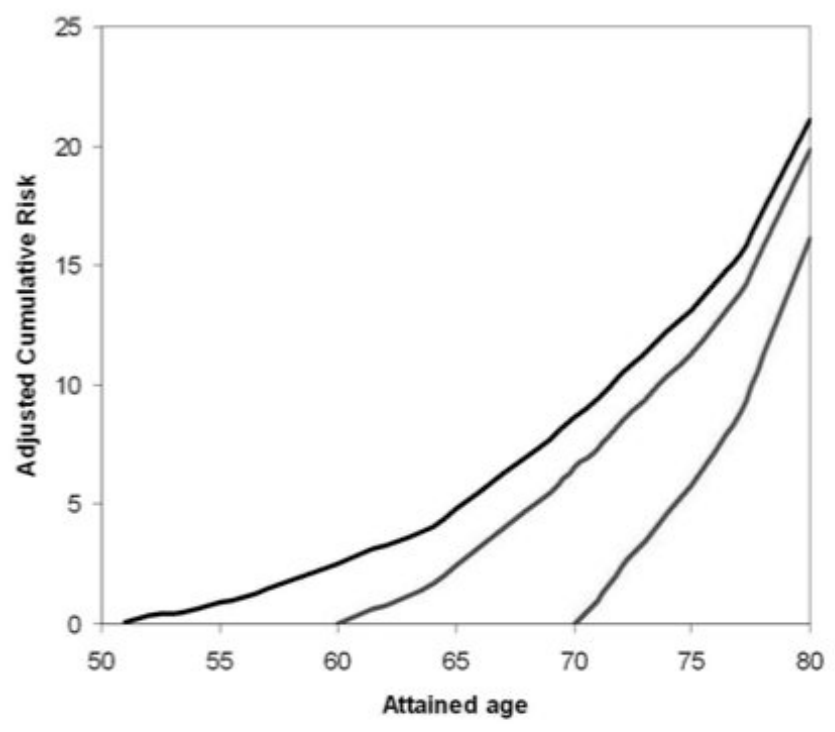

African-American men

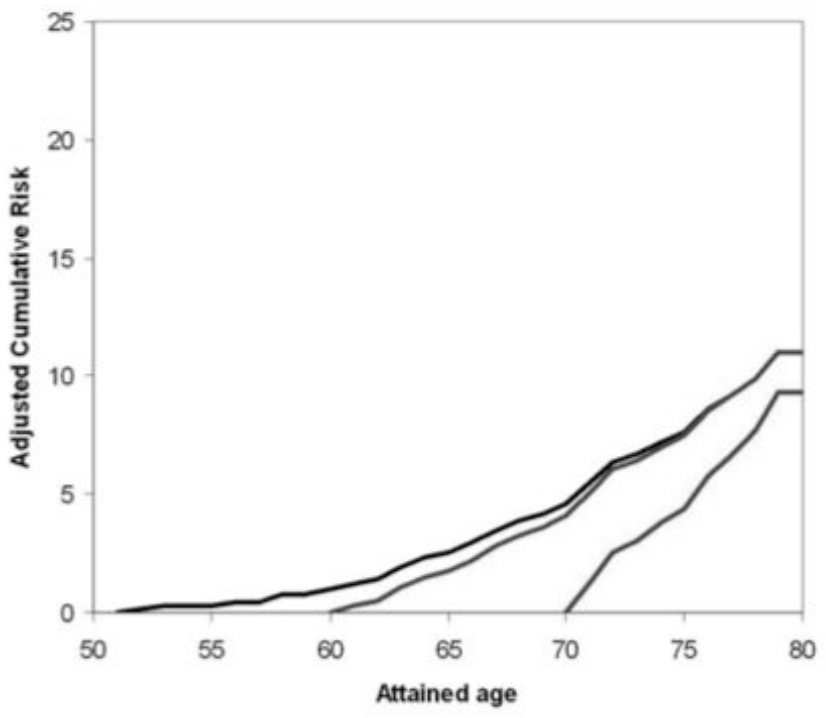

White women

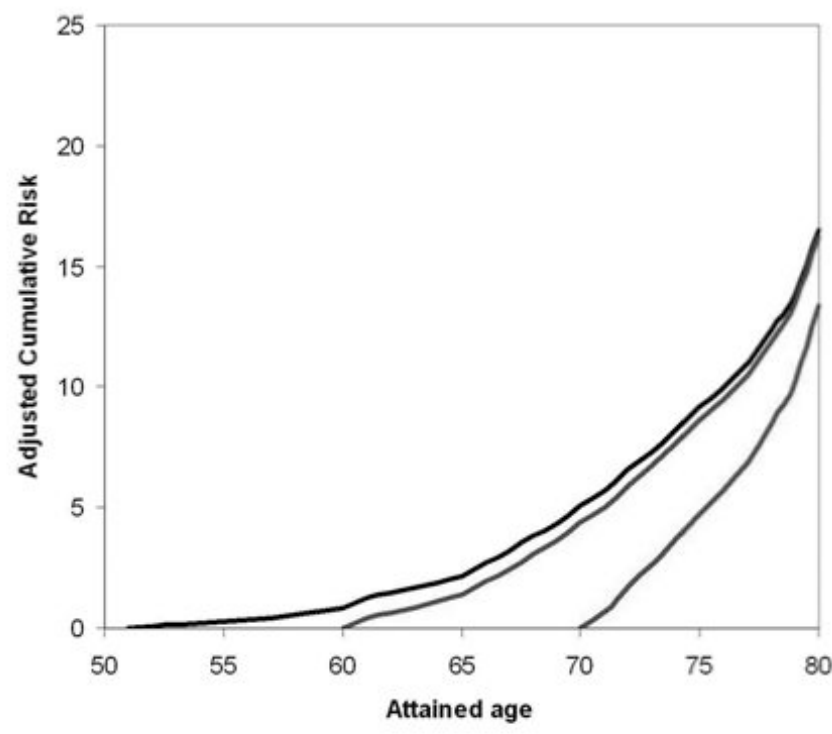

African-American women

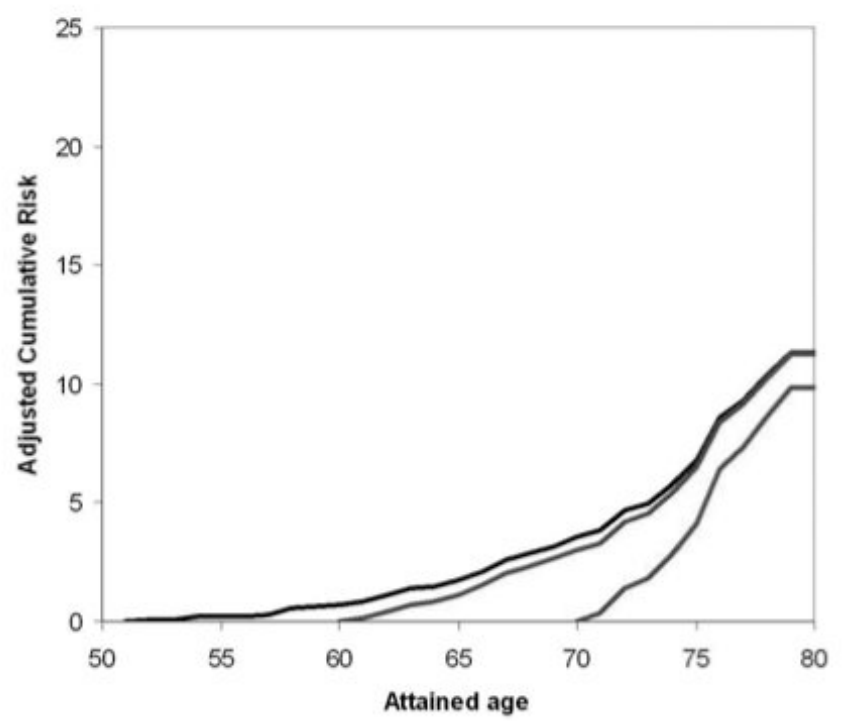

Figure 3.

Cumulative risk of atrial fibrillation (AF) at selected index ages for race- and sex-specific groups, with death free of AF considered a competing event. Lifetime risk for a given index age is cumulative risk through age 80 years, Atherosclerosis Risk in Communities Study, 1987-2004. 
Table 1

Selected characteristics of study participants at baseline, Atherosclerosis Risk in Communities Study, 1987-89.

\begin{tabular}{lcc}
\hline & $\begin{array}{c}\text { Whites } \\
\text { (n=11,292) }\end{array}$ & $\begin{array}{c}\text { African-Americans } \\
(\mathbf{n = 4 , 1 1 5})\end{array}$ \\
\hline Age (years) [mean (SD)] & $54.4(5.7)$ & $53.6(5.8)$ \\
Sex, \% women & 52.7 & 62.1 \\
Education, \% who are not at least & 17.2 & 41.6 \\
high school graduate & & $29.6(6.2)$ \\
BMI (kg/m ${ }^{2}$ [mean (SD)] & $27.0(4.9)$ & $168(8.9)$ \\
Height (cm) [mean (SD)] & $169(9.4)$ & 29.9 \\
Smoking, \% current & 24.8 & 56.0 \\
Hypertension, \% & 27.3 & 20.0 \\
Diabetes, \% & 9.1 & 5.5 \\
ECG LV hypertrophy, \% & 1.0 & 3.8 \\
Previous history of myocardial & 4.2 & \\
infarction, \% & & \\
\hline
\end{tabular}

BMI: body mass index; ECG LV: left ventricular hypertrophy assessed by electrocardiogram; SD: standard deviation 
Table 2

Sources of incident cases of atrial fibrillation (AF), Atherosclerosis Risk in Communities Study, 1987-2004

\begin{tabular}{lc}
\hline Source & AF cases [n (\%)] \\
\hline Hospital discharge code only & $958(88.3)$ \\
Exam ECG only & $21(1.9)$ \\
Death certificate only & $3(0.3)$ \\
Both hospital discharge code and death certificate, no exam ECG & $3(0.3)$ \\
Both hospital discharge code and exam ECG, no death certificate & $99(9.1)$ \\
Both exam ECG and death certificate, no hospital discharge code & $0(0)$ \\
All three sources & $1(0.1)$ \\
Total & $1085(100)$ \\
\hline
\end{tabular}

ECG: electrocardiogram 


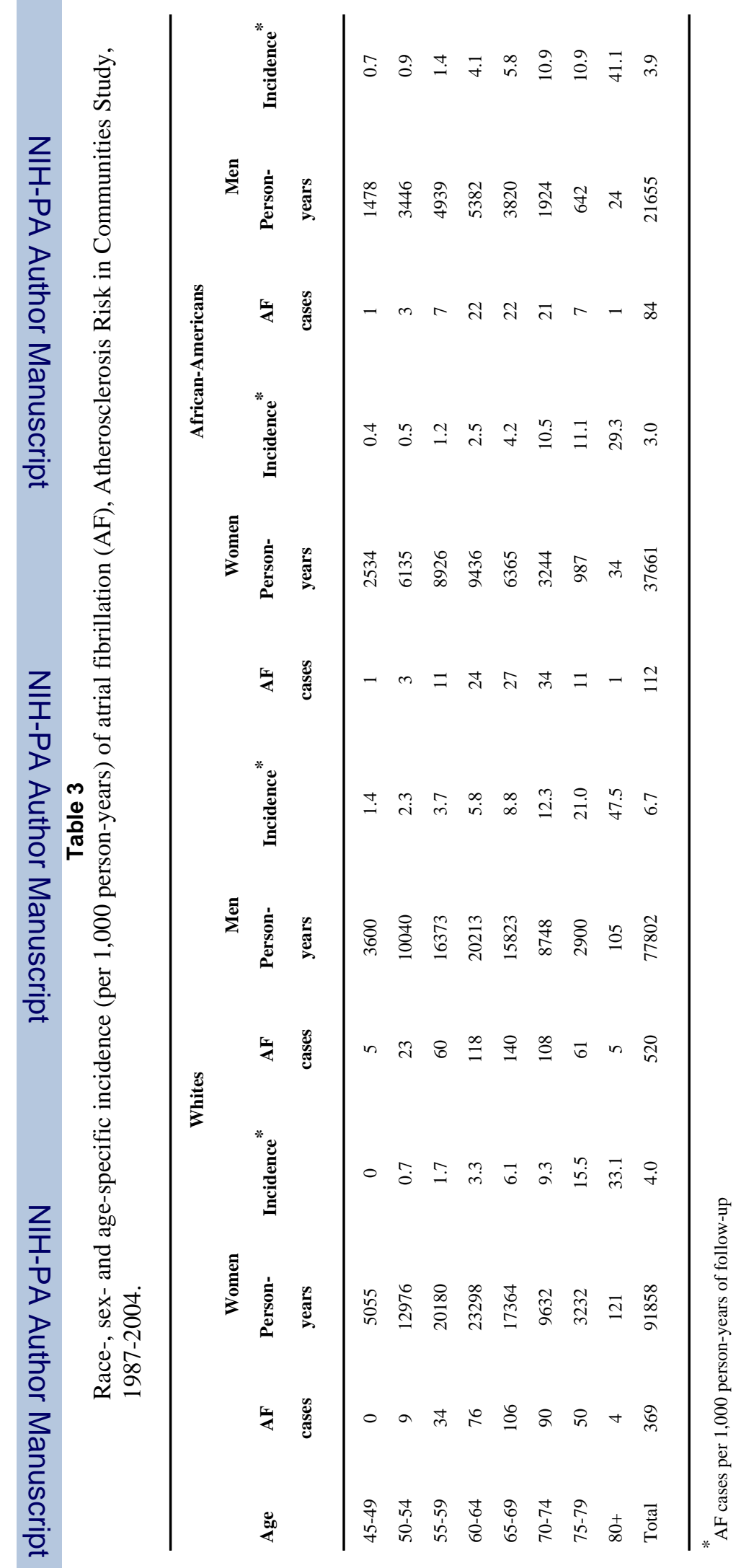




\section{Table 4}

Rate ratios of atrial fibrillation (AF) by race, age, sex, and period, Atherosclerosis Risk in Communities Study, 1987-2004.

\begin{tabular}{llll}
\hline & Rate ratio $^{\dagger}$ & 95\% CI & P value \\
\hline Race (African-American vs. White) & 0.59 & $0.38,0.92$ & 0.02 \\
Sex (men vs. women) & 1.54 & $1.37,1.74$ & $<0.0001$ \\
Age (5-year increase) & 1.65 & $1.57,1.74$ & $<0.0001$ \\
$<50$ & 1 & ref & \\
$50-<60$ & 2.98 & $1.39,6.37$ & \\
$60-<70$ & 7.97 & $3.75,16.95$ & 0.40 \\
$70-<80$ & 16.97 & $7.88,36.54$ & $19.17,134.0$ \\
$80+$ & 50.7 & $0.95,1.13$ & \\
Year $(5$-year period) & 1.04 & & \\
\hline
\end{tabular}

${ }^{\dagger}$ Poisson regression model adjusted for all the variables in the table.

\# Model including only AF cases identified through hospital discharge codes. 